\title{
12
}

\section{Documenting the link between policy theory and practice in a government department: A map of sea without any land}

\author{
Andrew Maurer ${ }^{1}$
}

\section{Introduction}

In 2015, I was asked to develop a document that described the approach of the Commonwealth Department of Communications and the Arts to policy development. It would be used as an input in a new training course for departmental officers delivered through the Crawford School of Public Policy. I was chosen partly because I was regarded as having great policy expertise within the department, and partly because I had worked with the human resources area previously in delivering internal policy training. Mostly though, I had recently been moved to a sort of 'odd jobs' position in which I was expected to do whatever was needed to make the department work more smoothly. This was one of those odd jobs. The three parts of this chapter describe:

- the department's changing structure and policy training needs

- considerations that influenced the drafting of a 'policy handbook'

1 Thanks to Dr Trish Mercer, Dr Russell Ayres and Professor Brian Head for their encouragement and guidance. Thanks also to the Department of Communications and the Arts for agreeing to this chapter being written. 
- the process through which the handbook was adopted as an accurate portrayal of departmental policy practice.

\section{My background}

My public service career up to this point had been moderately eclectic. Unlike many of my colleagues, after university I started in the Australian Public Service (APS) as a base grade clerk in a photocopy room, rather than entering through a graduate program. In the next 10 years I moved through a number of public service positions that might be seen as 'administrative' rather than 'policy' roles: trademark examiner, computer system tester, business analyst, technical writer, trainer, information technology team leader, internal auditor, project manager and general troubleshooter. I led a six-month mission in India for a United Nations agency, and then joined the Communications portfolio. Once there, I moved into a purely policy stream, mostly working in areas where the intersection of technology, law and economics called for new public policy approaches. After an interlude as the department's liaison officer in the minister's office, I returned to the department and led policy and program branches as well as areas responsible for international relations. When the department went through an extensive restructure, I spent a few months setting up a new policy branch, and then moved to a support role for the department's senior leadership-assisting with strategic planning, designing and implementing a new business planning process, and improving internal communication.

Mercer's (this volume, Chapter 3) description of a public service in which policy expertise is gained either through a mentored apprenticeship or serendipitous 'learning by doing' matches my experience. In my career, I had not received training in policy or policy theory. For the most part, when working as a policy officer, I was told to achieve a particular outcome and left to figure it out. Through practical work, I developed my own understanding of how to 'do policy' and got moved to increasingly difficult work at the conclusion of each task. There was an almost spartan 'with your shield or on it' attitude that is perhaps part of what contributes to the pragmatic mindset developed by policy practitioners in the public service. The work was a pleasure and a privilege, but at the same time I saw others develop very different concepts of a policy officer's role, and sometimes fail to develop a mental map of how to 'do policy' altogether. Over time, I sought out different descriptions of policy theory 
to better enunciate the underlying conceptual structure of my work. I read Productivity Commission reports on policy issues for insights on information gathering and analysis, and Australian National Audit Office administrative reviews to improve implementation techniques.

There came a point when I was transferred to lead a branch where the majority of staff were very good, but did not seem to understand why they were doing certain tasks - they did not have the mental context linking those tasks to an overarching policy process. I wanted to take the branch from a position where four or five team leaders and senior policy officers had policy expertise to a point where everyone in the branch was empowered to make an intellectual contribution to policy work. It was at that point that I really delved into policy theory, looking to build shared concepts of the policy process, and designing practical ways in which those concepts could improve the delivery of the branch's work. It provided something of a template for my later work on the departmental policy guide.

\section{The path taken}

For reasons noted below, I thought a useful approach for developing a departmental policy guide was to take one theoretical account of the policy process-Althaus, Bridgman and Davis's (2018) Australian policy cycle in their Australian policy handbook — and describe how different areas within my department contributed to each step of the cycle. It quickly became clear that, although I was developing a resource for the Crawford School course, the document could be a useful point of reference within the department itself to aid daily work during a time of extensive change. ${ }^{2}$

\section{Triggers and influences}

The brief I was given was simple: write a document describing the concepts and practices used by the Department of Communications when developing and implementing policy. There were a couple of immediate challenges:

2 In 2015, when the work being discussed here took place, the 2018 edition of The Australian policy handbook was not in existence; an earlier edition of the text was used. The most recent edition is referenced here for ease of access for readers who wish to follow up the reference. 
- The department included various localised areas of expert policy practice, but did not have a department-wide approach-policy skills were mostly developed through a mixture of 'apprenticeships' and learning through doing.

- The department had undergone an extensive restructure that had shaken up all previous practices and corporate knowledge.

There were, however, some countervailing circumstances that could assist the exercise:

- The Australian Public Service Commission (APSC) had recently conducted a capability review of the department, which documented some clear strengths and made straightforward proposals to further improve the department's policy capabilities and practices.

- The departmental restructure had involved the creation of new areasa chief economist-led research bureau, and separate market analysis teams - to improve the department's evidence-based policy capacity.

- After months of uncertainty, there was a strong appetite among the department's staff for any information or guidance that would establish 'a new normal' for how teams would interact with each other and how the department as a whole would successfully undertake its work.

There appeared to be an opportunity to deliver a 'policy handbook' that would not only be useful for the Crawford School's 'Policy Essentials' course, but would also address issues raised by the restructure, the APSC Capability Review and the ongoing operational needs of the department.

\section{Restructure}

The department went through extensive change in 2014 and 2015. Staff numbers across the board were reduced by 30 per cent, and all remaining policy positions were reshuffled so that most policy staff were working on different subject matter and in a newly formed team. Policy teams were further reduced in size to contribute staff to a new 'Bureau of Communications Research' led by a chief economist, and to create separate 'market analysis' teams with commercial knowledge and technology expertise.

The intent of the restructure was to move from having policy areas that specialised in communications industry sectors (i.e. telecommunications and broadcasting) to a model that holistically addressed cross-cutting 
policy issues (i.e. infrastructure, competition, consumer protection and content). There was to be greater consideration of the communications sector's contribution to the wider economy-reflected in the creation of the economic and commercial teams, as well as a new 'digital productivity' division. A great emphasis was placed on the department moving from a program and policy function to being a pure policy department.

All of this would require a new way of working - a division of labour would be applied to policy development. Reduced-size policy teams would no longer have to possess an all-round skillset; however, through communication and collaboration with other areas (particularly the research bureau and market analysis teams), they were expected to deliver superior results.

\section{Review}

The APSC, an agency tasked with ensuring that the public service is sustainable and effective in carrying out the work of government, had been undertaking a series of 'capability reviews' of government agencies since 2011. It developed a standardised framework to describe capability (see Figure 12.1), and agencies were individually evaluated in terms of leadership, strategy and delivery. The APSC undertook a capability review of the department while it was being restructured.

Given its timing, the APSC based its capability assessment on the department's future plans and how well it was tracking towards the outcomes of the restructure (APSC 2015, p. iv). The February 2015 report was positive about the department's ability to deliver government agendas, and optimistic about how the restructure would improve on that capability.

The review identified several areas for improvement, and advised that staff needed a better explanation of how the new structure and new ways of working would operate on a day-to-day basis. There needed to be improved mechanisms to plan and collaborate on work shared across different areas, and to track the achievement of objectives. The review also noted that the department's reliance on local 'policy apprenticeships' had a certain utility, but was not sufficient for its future ambitions. Managers needed additional support in mentoring their teams' policy skills, and there needed to be a more systematic approach that built a consistent set of skills across the department. 


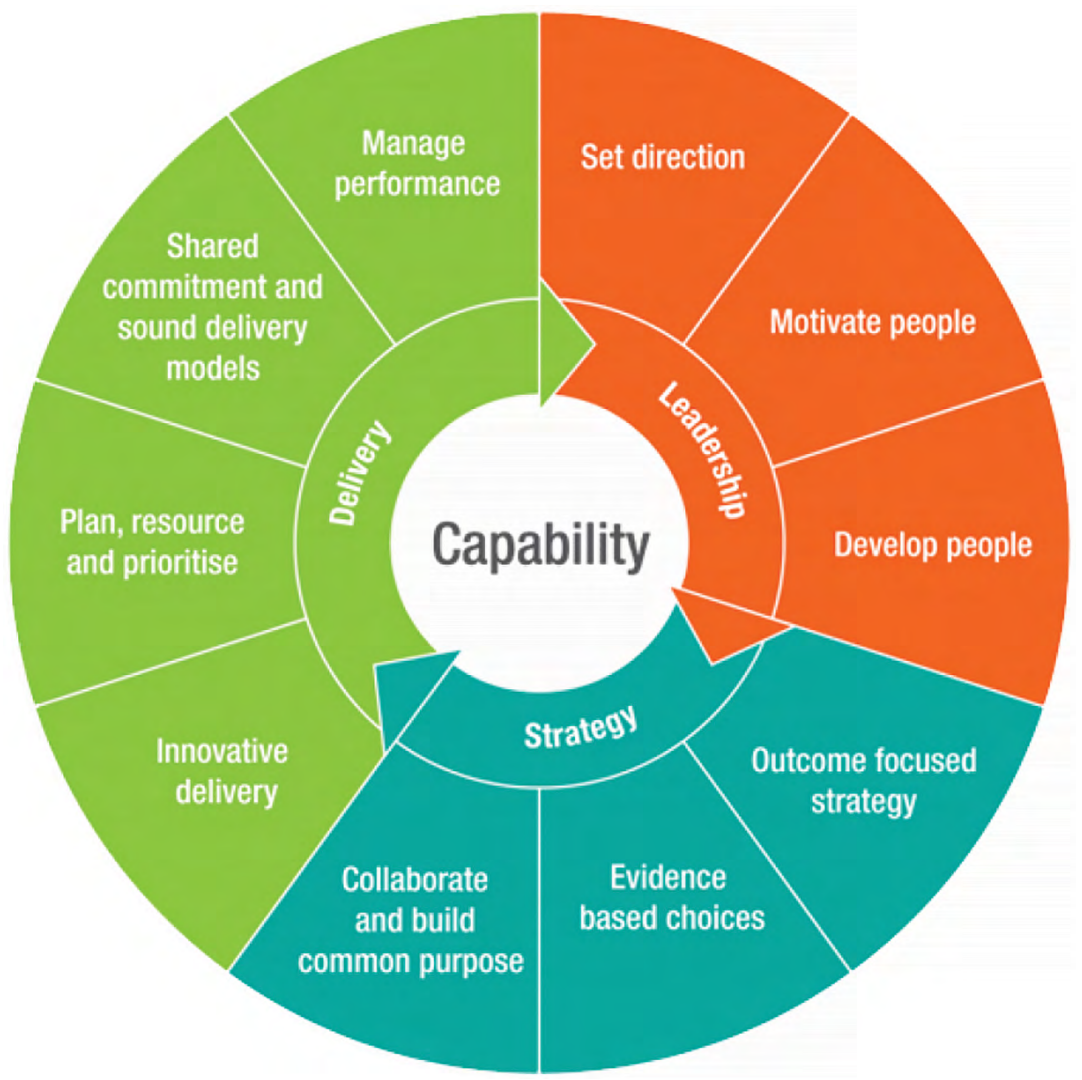

Figure 12.1. APSC model of capability.

Source: APSC (2015).

\section{Further change}

In September 2015, the department changed minister and secretary. The Digital Productivity Division was moved to a different government portfolio. The Ministry for the Arts was brought into the department as a policy and program division. Incoming staff were keen to get an idea of how the department, now called the Department of Communications and the Arts, conducted its work, and how to navigate its structure. Having gone through two years of restructure and uncertainty, remaining staff had the sense that, once again, they were in a very different department. They too wanted a guide to what the 'new normal' would be. 


\section{Developing a policy handbook}

Policy is enunciated in rhetoric; it is realized in action. (Kaufman 2006, p. 3)

During the restructure, the secretary of the department, Drew Clarke, established an executive committee consisting of himself, his two deputy secretaries and their direct reports, the department's first assistant secretaries. The executive committee addressed departmental resourcing and strategic management, and, at a high level, the development and implementation of policy. In May 2015, Clarke and the executive committee asked me to develop a document that would be used by the Crawford School's 'Policy Essentials' course. I provided progress reports to the executive committee as the work proceeded.

Initially, the request envisaged the target audience for the document to just be the new policy officers attending the course and the lecturers delivering it. However, the people attending the course would be working with other policy officers in teams led by experienced managers and practitioners. Those teams, in turn, were grouped by subject matter into branches led by assistant secretaries, who reported to the department's first assistant secretaries. These branch heads and team leaders were the ones making detailed plans and managing the day-to-day work of policy officers. No-one wanted there to be a disconnect between what people were taught in the Crawford policy course and their lived experience in the department, so the target audience was broadened to include all policy officers, team leaders and branch heads, as well as those areas that were not directly involved but provided support to the department's policy work.

\section{Scope}

I had been asked to document the department's approach to policy development. The reality was that an explicit departmental approach did not exist. For the most part, good policy work was done through individuals acquiring a thoroughgoing knowledge of the subject matter at hand, and an informal culture of collaboration and ad hoc information exchange. Individuals had their personal mental constructs that they used as a framework for organising their policy work, and long-established teams tended to share and follow common practices. The department's restructure meant that a lot of assumed and implicit knowledge fell away, as did the informal channels of communication and cooperation. 
Obviously, branch heads, team leaders and their teams would work to re-establish these networks in the course of their daily work, but it would be a slow, organic process, made more tentative by the fact that everyone was learning new subject matter. The policy handbook was an opportunity to provide some points of common reference and signposts for the people creating new norms for departmental work and policy capability.

\section{Process}

The policy handbook went through a few iterations. In late May 2015, I circulated the first draft to the people leading departmental branches, the research bureau and the market analysis teams, and then held meetings to brief them on the content and purpose of the handbook. I suggested that they discuss the draft with their branches and teams and encouraged them to make changes-particularly in the chapters that described different areas' roles and how they would work together in delivering policy outcomes. There were a lot of proposed changes, mainly because people started treating the descriptions of areas' responsibilities and modes of interaction as a roadmap for their everyday interactions.

Over several weeks, I redrafted the various suggestions into a coherent version, and released it as an editable 'track-changes' draft to the entire department. I also provided progress reports to the department's executive committee, and to the department's audit committee. There was a brief period of renewed drafting, consultation and briefing during machineryof-government changes in September and October 2015; this is when the Ministry of Arts was incorporated into the renamed Department of Communications and the Arts. The final product was provided to the Crawford School of Public Policy to use in the training course it was delivering to departmental staff, and republished on the department's intranet in November 2015.

\section{Drafting}

The policy handbook mapped the department's different work areas and described their operation using the Australian policy cycle as the organising principle. The handbook contained four chapters:

1. an introduction that outlined the purpose of the document

2. a description of the department's structure, and the thinking behind the division of labour between policy teams, market analysis teams and the research bureau 
3. a thumbnail sketch of Althaus, Bridgman and Davis's (2018) policy cycle, illustrated by a description of the roles, actions and interactions of different areas of the department at each stage of the cycle

4. a final chapter describing 'additional practices within the department' that, strictly speaking, were not existing practices, but were additional reflections on policy techniques and theory that arose when drafting the handbook.

\section{Why choose the Australian policy cycle?}

There were several reasons that I used the Australian policy cycle as the foundation for the department's handbook. As a theoretical construct, it attempted to cover the entirety of the policy process, rather than 'deepdiving' into a single aspect. As a policy practitioner, I could not see a step in the cycle that I could readily omit, or additional material that needed to be added - it had a good internal logic and practitioners could see its relevance to most of the daily activities involved in policy development. I particularly liked the fact that it did not merely describe and analyse past policy work, but could be used as a tool to design new policy processes and to develop supporting project plans and work structures. To my mind, the Australian policy cycle was very well suited to planning and coordinating the work of multiple people or several teams: there was not an implicit assumption that a single entity would make decisions or undertake work all the way through.

Finally, I wanted the policy handbook to be used by the entire department, not just those attending the Crawford policy course, so it needed to overcome any innate scepticism about policy theory, and be taken on board by stressed people learning new subject matter in a new job. The basics of the Australian policy cycle could be readily picked up, and I felt that people with a reasonable amount of policy experience could feel confident in training others in it, or explaining their current work in its terms. Although not extensively cited in day-to-day work, I could point to examples of the policy cycle being referenced or utilised in work across the APS, and the extent of its adoption made people more confident in its legitimacy and utility.

\section{The role of policy theory in the APS - a riddle wrapped in a mystery inside an enigma}

The Australian policy cycle has clear strengths; however, in academic literature, it has also drawn criticism (summarised nicely in Mercer this volume, Chapter 3) for providing far too simple, idealistic and linear 
a picture of policymaking. The reality of policymaking involves a far greater complexity of action and policy actors. Cairney somewhat provocatively suggests that 'policymakers engage in a policy process over which they have limited knowledge and even less control ... we need to give up on models that project simplicity and central control (such as the policy cycle)' (Cairney this volume, Chapter 13). In the case of the department's policy handbook, why not use a model that emphasises complexity and the absence of central control?

Cairney (this volume) notes a divergence between policy theories that 'help explain policymaking rather than seek to promote what should ... happen'. I think the distinction between the more advanced theories that help explain policy, and those that help do policy is a useful one.

In seventeenth-century Russia, there was a concern in some quarters that masses were taking too much time-some liturgies were up to eight hours long. It was considered wrong to skip any elements, so the cunning solution was to split the liturgy into smaller parts and have them all sung at the same time by different teams of priests. Masses were admirably fast, all elements of the liturgy were present. Unfortunately, from the congregation's point of view, this practice of mnogoglasie made masses a mad, incomprehensible cacophony with up to six teams of priests trying to make themselves heard and the beginning, middle and end of the mass happening at the same time. The priests generally knew what they were doing and why, but it was impossible for congregations to either understand what was going on or to meaningfully participate.

Policy work in government can be equally confusing. Language can be arcane, many activities are conducted in parallel and it is not always clear to participants how different activities relate to the overarching public policy process. The Russian Church eventually put aside mnogoglasie. In the public service, and possibly in all policymaking, it is here to stay. From my perspective, the Australian policy cycle's selling point is that, for policy novices, it brings clarity out of pure howling chaos. The recognition and comprehension of key concepts enables meaningful participation; this in turn leads to a more sophisticated understanding of policy and the policy environment. For the more experienced practitioner, it provides mental maps and concepts that can be used as an organising principle when planning and undertaking policy work. The fact that those maps and concepts are held in common with other practitioners enables collaboration across the organisation. 
It was my view that a policy theory that emphasised complexity and lack of agency might be more accurate but would not enable proactive and confident policy work to be pursued consistently across the department. Essentially, the Australian policy cycle as described by Althaus, Bridgman and Davis (2018, para 21) is 'a heuristic ... designed to help answer the daunting question "What do I do now?". At the time of its restructure, that was exactly what the Department of Communications and the Arts needed. The policy handbook was intended to be the starting point, not the culmination, of building policy capability in the organisation. This meant that its primary value would not be in its content, but in how it was read and used by its audience. Focusing on its audience, the handbook needed to:

- introduce novices to essential policy concepts

- give more experienced practitioners a shared language for describing policy work

- establish common expectations of how policy areas would work with each other

- provide the Crawford Policy School a point of departure to explore a more complex world of policy.

However, it was highly dependent on the concepts described in the handbook being incorporated into the department's everyday work.

\section{Deployment}

To be successful as a departmental resource, the handbook needed to be supported by the people who coordinated the work of policy officers- the branch heads. Both Cairney (2015) and Ayres (this volume, Chapter 8) have described a certain innate scepticism about policy theory among policy practitioners in the public service. At the beginning, there were similar sentiments from the branch heads, not from any sort of antiintellectualism, but reflecting different concerns, namely, that the policy theory in the handbook would not do enough or that it would do too much. On the 'not doing enough' front, there was the worry that the use of policy theory would not improve the quality or ease of doing policy work, but would require additional time and effort so that people could demonstrate compliance with a newly minted but untried departmental approach to policy. On the 'doing too much' side, there was a worry that 
people in the department might be so concerned with following steps laid out in the handbook that they would not exercise judgement or develop their own expertise in the course of policy work.

\section{Selling points}

The branch heads' most pressing concerns were largely allayed when they read the handbook - their fears of a complex document requiring the doctrinaire application of irrelevant checklists had not eventuated. However, they were still lukewarm on the document. Many remained dubious about how the policy theory component of the handbook would be applied in their daily work. My initial thought was that unless there were some very clear 'selling points' that showed the policy cycle's utility for their future work, the branch heads might be inclined to ignore that part of the document.

I prepared (and tried) various arguments and explanations, but it became clear that regardless of how eloquent or well-reasoned my talking points were, they were not doing the job; it was less a question of whether the policy handbook was acceptable to the branch heads, and more a question of whether they were intellectually and emotionally ready to accept it. Advocacy from the author of the handbook was going to be taken with a grain of salt or discounted altogether. I decided instead to focus on giving the branch heads and the rest of the department a mechanism to build their familiarity and ownership of the handbook. The parts of the handbook covering the role and interactions of different areas of the department were regarded as having practical use and interest. I encouraged the branch heads to discuss with each other whether these parts of the handbook were accurate, and to return with edited text.

\section{The handbook becomes a source of truth}

The branch heads were quite positive about meeting to discuss the roles and interactions of different areas of the department. The new areas- the research bureau and the market analysis teams-were particularly keen to have their function documented and understood in the department. However, immediately following the restructure, they did not have work on hand to discuss and negotiate with the different areas of the department. Many parts of the department had the same issue. During the restructure, most areas had focused on tying up loose ends so that their successors would have an easier transition. It changed the nature of discussions. 
In the absence of an immediate task that needed doing, most areas in the department found that the Australian policy cycle provided a good proxy to outline how future work would be handled.

In my initial draft, I had attempted to make the descriptions of different areas' contribution to the policy process as clear as possible, but had made it plain that I would be very happy to accept any change that improved accuracy and clarity. There was an initial flurry of edits as people suggested additional detail to describe their areas' responsibilities. This was followed by a slightly smaller flurry of reversions back to the original text. I had not expected it, but as soon as the handbook was released to branch heads for comment and update, it was latched onto as an authoritative guide to who within the department should be doing what work. The handbook was simple, it was practical and there was no other written description of how the department should work. People believed its narrative and started making choices based on it. The 'division of labour' approach to policy work was new and had some teething issues to work out. The handbook was used as a commonly agreed starting point when arbitrating disagreements between areas about how to take work forward. This meant that people were cautious about claiming too much (or too little) of a role in the policy process, and quickly became aware that any sweeping changes they put forward would be the subject of forensic scrutiny and discussion with the other areas they would be working with. The majority of edits ended up clarifying points of demarcation and making sure the descriptions of work would not be misconstrued by team members or by the department's senior leadership.

The process of wrangling out respective roles, responsibilities and expectations meant that people did not focus too much on critical analysis of the handbook's theory component-the policy cycle. They used the handbook as a whole as a starting point for their discussions and grew comfortable with treating the policy theory component as 'a given'. I think it established a usefully pragmatic attitude: the policy cycle was increasingly regarded as a useful heuristic rather than an omniscient oracle. It was not a set of instructions to be followed by each different policy team in every circumstance, but instead provided a consistent overall structure and set of concepts that could be used when planning future work. 


\section{Further feedback - the 'selling points' show up at last}

From my perspective, a major change in the branch heads' collective view of the handbook came around the time of the first flurry of edits. I had approached a couple of people who I regarded as policy mavens: expert, fascinated by all aspects of the policy process and highly respected in the department. I asked that they reflect on what the department needed from the document and provide an unvarnished critique of the handbook to their fellow branch heads. One of them sent a late night email with some points that strongly influenced the subsequent edits suggested by branch heads. The points were:

- The handbook was written in a lively style. Descriptions were brief, clear and to the point. This should be maintained. Individual areas could put more detail in their business plans or internal documents if they wanted, but it was not desirable for the handbook.

- The Australian policy cycle was a well-structured, pragmatic construct that could readily be used to train staff in policy work.

- Linking the policy cycle to the department's structure and operation was a good idea, as it helped the theoretical component feel 'real'.

- The fact that the Australian policy cycle was relatively well known meant that it would be useful in discussing work with a variety of stakeholders.

- The description of the role and interaction of different areas of the department would be useful in orienting staff to the restructured department.

- People should be wary of 'drafting by committee'-inconsistencies and double-ups had crept in when different areas had edited the text.

- Although the handbook and the policy cycle both made it clear that policy development did not consist of a fixed sequence of actions, it would be good if that message were emphasised. Novice policy practitioners tended to apply the things they learnt in a mechanical fashion. Adaptability and judgement were key. Checklists and anything that implied a rigid sequence should be avoided.

I think that, unconsciously, the branch heads had started to accept the handbook. The late night email perceptibly repositioned the branch heads' conscious thinking about the document. They no longer approached the handbook as a passive audience; they started thinking about it as a tool 
to be used-whether to negotiate roles across the department, develop their staff or communicate the nature of their work with internal and external stakeholders.

\section{Organic circulation and an anticlimactic launch}

As part of their collaboration and consultation across different areas, teams and branches started describing their future work to each other in terms of the policy cycle-it was increasingly being used as a common language across the department's policy work. When I redesigned the department's business planning process (another odd job that I had been assigned) or briefed the audit committee on the department's response to the APSC Capability Review, I included cross-references to material covered in the handbook. It meant that, when departmental staff undertook business planning or reporting to the audit committee, they could do so using the handbook's structure and concepts as a commonly understood frame of reference. The policy cycle was subtly becoming pervasive and, at the same time, less exciting and less foreign. People were using it to plan future activities in a matter of fact way-they were not thinking about it as a theoretical model, but as a way of organising policy work that was congruent with the way the department did things.

At the beginning of the consultation process, I had encouraged branch heads to give early copies of the handbook to their staff: some did, some did not. During the course of discussions between different areas of the department, everyone was talking about future work in terms of the handbook's contents, and branch heads and section heads often continued to use the same language and concepts for their areas' internal planning. Staff involved in these planning sessions had a very strong sense that, if they read the mysterious handbook that was being alluded to, they would have an inside track on understanding what was going on. The more enterprising staff that had not yet received a copy started seeking it out, either from me or from fellow staff in areas where it had been more generally shared. They also tended to make a point of passing it on to their friends and colleagues.

As it became apparent that slightly different versions were starting to circulate, I released a final draft to the entire department for a last round of review and comments. By this stage, the Ministry of Arts had joined the portfolio. Their response was that the handbook was useful for orienting staff to how the department worked, and that the way they worked matched (more or less) the policy cycle, although they had not 
referenced it as explicitly as the rest of the department seemed to. The rest of the department seemed a bit puzzled by the final round of consultation. The handbook accurately described the policy process and division of policy work between areas; it matched what everyone knew-what more was needed?

The final release of the document in November 2015 was pleasantly lowkey. A copy was added to the department's intranet, and a copy provided to the Crawford School of Public Policy so that they could include it in the new policy course they would deliver to selected departmental staff.

I had early feedback from course participants: the handbook helped them to better understand the department and matched how their fellow team members and their managers were tending to talk about policy development. However, they would have liked to see some checklists or flowcharts to use when they returned to work.

I had been using the department's electronic file management system to keep track of accesses and edits to the handbook during the consultation phase. There had been a lot of different people reading it in the month immediately before and after its finalisation. After that, the number of people accessing the document dropped off, with some upticks each time a new Crawford Policy School course started (interestingly, it was not just course attendees who were opening the document), each time we had an influx of new staff or graduates join the department, and at certain stages in the annual business planning process. Mostly though, the contents of the handbook seemed to have become the 'new normal' for the department, and the document itself did not need to be referred to.

\section{Conclusion: Reflections on policy theory and the policy handbook}

I was asked to document the department's approach to policy, and found that, while there was a diversity of policy practitioners, some highly expert, there was no universally held theory or practice. Instead, there was a certain mystique attached to policy work and what Ayres describes as "being inside the "black box" - a combination of everyday experience and implicit knowledge that meant some and not others were regarded as possessing a 'policy brain' (Ayres this volume, Chapter 8). 
The APSC Capability Review had identified that the department's traditional approach of policy apprenticeships and 'learning by doing' worked to a certain extent, but that to strengthen the organisation's capability, a more systematic approach was needed. I have not mentioned it previously, but there were a series of publications questioning whether the APS more generally had been suffering a decline in public policy capability, institutional memory and, on an individual level, the analytical and communication skills needed to fulfil its role in the Australian polity (Behm 2015; Button 2012; Shergold 2015; Tingle 2015). There was a degree of self-examination within the department on whether these concerns were true, and what might be done. At the same time, all previous practices and corporate knowledge had been shaken up by a radical restructure and downsizing, which had taken close to a year to put in place. People wanted to know how the restructured department would operate, so they could get on with their work. A clear map of how things would work on a day-to-day basis did not exist. The handbook needed to address a present organisational need.

\section{Was the handbook a success?}

From my perspective, the most substantive work associated with the handbook was undertaken by the branch heads and team leaders when they adopted its concepts into everyday practice. The text of the handbook did not change radically between its first draft and final release, but in that time I saw it move from being a dubious and theoretical document, to a charter for how things ought to be, to a basis for negotiating work and, finally, ending as a factual report of how policy work was handled in the department.

I would say that the handbook was most successful when it was still being edited and haggled over. The inclusion of the policy cycle gave the handbook a clear structure and intellectual rigour. The matching description of roles and responsibilities within the department made the theoretical component relevant to the handbook's audience. The fact that everyone knew the handbook's contents, and everyone was using it, was the thing that made it real. The policy cycle became a common language across the department, people knew their own role and the role of other areas, and there were clear structures for communication and collaboration to take work forward. 
Jorge Luis Borges (1985) wrote a short story, 'On exactitude in science', about an empire that sought to create more and more accurate maps of its territory: 'the Map of a Single province covered the space of an entire City, and the Map of the Empire itself a single Province'. These were regarded as deficient and so the cartographers created a map that was precisely the same scale as the empire. It proved too cumbersome to use or maintain over time, and so the story reports that it was abandoned.

There are a lot of thoughts that can be taken from the story, such as: when you have the reality of lived experience, you do not need a 1:1 map. The readership of the handbook declined over time, partly because the reality it described was so apparent and well understood. Perhaps a more positive way of looking at it is put forward by Althaus, Bridgman and Davis (2018, para 19) in the introduction to their text:

The policy cycle is just a starting point for understanding. Its role is to teach policy to those for whom it is not a familiar companion from a lifetime of practice and study ... a simple model helps order reality and provide a sense of direction ... With time, it may seem too simple — but by then the model has done its work.

The departmental handbook was something that individual policy practitioners could learn from, internalise and grow beyond.

From an organisational perspective, the success was having the department adopt commonly understood policy concepts and heuristics, and build a larger pool of people with a shared understanding of the fundamentals of the agency's policy work. The challenge in future will be entropy: humans forget and organisations change. New staff join, other staff move on, organisational structures and everyday practices adapt to meet new needs. Maintaining the currency of written documentation can be nearly as onerous as Borges's map. Periodic mechanisms like the APSC Capability Review may operate as a suitable trigger for agencies to identify when their policy capability needs to be refreshed.

\section{References}

Althaus, C, Bridgman, P \& Davis, G 2018, The Australian policy handbook: A practical guide to the policy making process, 6th edn, Allen \& Unwin, Sydney, NSW. 
Australian Public Service Commission 2015, Capability review: Department of communications, viewed 10 January 2020, www.apsc.gov.au/capabilityreview-department-communications.

Behm, A 2015, No, minister: So you want to be a chief of staff? Melbourne University Press, Melbourne, Vic.

Borges, JL 1985, 'On exactitude in science', in NT di Giovanni (trans.), A universal history of infamy, Penguin Books, Harmondsworth, UK.

Button, J 2012, Speechless: A year in my father's business, Melbourne University Press, Melbourne, Vic.

Cairney, P 2015, 'How can policy theory have an impact on policymaking? The role of theory-led academic-practitioner discussions', Teaching Public Administration, vol.33, no. 1,pp. 22-39, doi.org/10.1177/0144739414532284.

Kaufman, H 2006, The forest ranger: A study in administrative behavior, Resources for the Future, Washington, DC.

Shergold, P 2015, Learning from failure: Why large government policy initiatives have gone badly wrong in the past and how the chances of success in the future can be improved, APSC, Canberra, ACT.

Tingle, L 2015, 'Political amnesia: How we forgot how to govern', Quarterly Essay, 60, Black Inc., Collingwood, Vic. 
This text is taken from Learning Policy, Doing Policy: Interactions Between Public Policy Theory, Practice and Teaching, edited by Trish Mercer, Russell Ayres, Brian Head and John Wanna, published 2021 by ANU Press, The Australian National University, Canberra, Australia.

doi.org/10.22459/LPDP.2021.12 